\title{
КАК ПОВЫСИТЬ КАЧЕСТВО И ДОСТУПНОСТЬ ОБРАЗОВАНИЯ ДЛЯ ВСЕХ ОБУЧАЮЩИХСЯ. ИЗ ОПЫТА РАБОТЫ
}

\section{HOW TO IMPROVE THE QUALITY AND ACCESSIBILITY OF EDUCATION FOR ALL STUDENTS. FROM EXPERIENCE \\ O. Khlopkova}

Summary: For several years, the author has been working on the problem of developing a model of a system to improve the quality and accessibility of education for all students of secondary schools. The model consists of three stages and covers three groups of participants in the educational process: students, teachers, and administration. When it is implemented, each stage is modernized, increases the number of tasks set and solved, leading to the final goal - to improve the quality of the educational process in the school, to provide affordable forms of its implementation.

Keywords: educational development, model, improving the quality of education, accessibility of education, professional growth, quality management.
A ктуальность статьи обусловлена изменениями в системе общего образования в связи с реализацией государственной программы Российской Федерации «Развитие образования на 2018 - 2025 годы», целями которой является качество и доступность образования, реализацией проекта «Учитель будущего» в рамках Национального проекта «Образование». Национальный проект РФ «Образование» направлен на:

- Внедрение в общем образовании новых методов обучения и воспитания, образовательных технологий, обеспечивающих освоение обучающимися базовых навыков и умений, повышение их мотивации к обучению и вовлечённости в образовательный процесс.

- Это возможно при внедрении национальной системы профессионального роста педагогических работников, охватывающей до 2024 г. не менее 50 процентов учителей общеобразовательных организаций.

Составной частью системы профессионального развития является независимая оценка квалификации педагогов, а также изменения в порядке аттестации педагогических кадров.

Независимая оценка квалификации соответствует требованиям профессионального стандарта педагога. Профессиональное развитие каждого педагога должно
Хлопкова Оксана Викторовна

Аспирант, Академия социального управления (г.Москва) okshlopkova3@bk.ru

Аннотация: На протяжении нескольких лет автор работает над проблемой разработки модели системы по повышению качества и обеспечению доступности образования для всех обучающихся общеобразовательной школы. Модель состоит из трех ступеней и охватывает три группы участников образовательного процесса: обучающихся, учителей и администрацию. При ее реализации каждая ступень модернизируется, увеличивает количество поставленных и решаемых задач, приводя к конечной цели - повышению качества образовательного процесса в школе, предоставлению доступных форм его реализации.

Ключевые слова: развитие образования, модель, повышение качества образования, доступность образования, профессиональный рост, управление качеством.

носить личностно ориентированный характер, который возможен при создании индивидуальной траектории повышения квалификации в разных формах и технологиях. Значительную роль в организации новых форм повышения квалификации педагогов играет работодатель - администрация образовательного учреждения.

Управление организацией напрямую связано с управлением качеством и доступностью образовательного процесса, что невозможно без повышения квалификации педагогических кадров. Проблема качества и доступности образования для всех детей не нова. Данной проблемой автор занимается более десяти лет. Проблема - разработать модель системы по повышению качества и обеспечению доступности образования - апробировалась в течении 10 лет в 4 общеобразовательных школах города Москвы и Московской области, в ней участвовали 900 обучающихся 1-7 классов и 128 педагогов. Модель системы по повышению качества и обеспечению доступности образования состоит из трех ступеней и охватывает три группы участников образовательного процесса: обучающихся, учителей и администрацию. При реализации модели каждая ступень модернизируется, увеличивает количество поставленных и решаемых задач, приводя к конечной цели - повышению качества образовательного процесса в школе, предоставлению доступных форм его реализации. 


\section{1 этап диагностический.}

На данном этапе происходит диагностика результатов деятельности всех групп участников для определения глубины решения задач при достижении главной цели. Длительность первого этапа определялась административным менеджментом в организации и была от полугода до года.

\section{2 этап практический.}

На втором этапе проводилась работа по повышению качества образования, исходя из результатов мониторинга деятельности учащихся, педагогов, администрации, создается направление дистанционной работы, программы внутрикорпоративного повышения квалификации. Длительность второго этапа - один учебный год.

\section{3 этап развивающий.}

На данном этапе происходит расширение, дополнение имеющихся направлений работы: развитие дистанционного обучения, тьюторского сопровождения обучающихся и педагогов, партнерских соглашений с внешними организациями. Длительность третьего этапа зависит от руководства образовательной организации по реализации программы развития школы.

Рассмотрим этапы модели системы по повышению качества и доступности образования в образовательном учреждении более подробно.

\section{1 этап Аиагностический}

Цель первого этапа - выявить информацию о реальном состоянии дел в образовательном учреждении на основе результатов мониторинга деятельности обучающихся, уровня профессиональной компетентности педагогов, системности работы администрации по постановке и реализации задач развития образовательного учреждения.

Важной информацией для начала деятельности по созданию Модели являются результаты мониторинговых мероприятий, проводимых администрацией школы в рамках внутришкольного контроля. У обучающихся школы:

1. Выявляется уровень знаний программного материала по учебным дисциплинам. Он анализируется в течении учебного года, охватывая основные контролируемые элементы (темы рабочей программы по предмету) и показывая проценты их усвоения учениками класса. Сводная таблица анализа позволяет увидеть рейтинг класса и по другому критерию - средний процент усвоения всех тем каждым учеником класса. Данная таблица анализа диагностики по предмету позволяет увидеть сравнительную характеристику класса учителю и администратору школы, вычленить индивидуальные результаты по каждому ученику, построить программу индивидуальной работы с обучающимися по освоению тем учебных дисциплин.

2. Анализ результатов мониторинга логических умений позволяет субъектам образования (администрации, учителям, родителям и пр.) получить полное представление об уровнях их сформированности у обучающихся в классе в целом, у каждого обучающегося индивидуально и позволяет сделать выводы, которыми руководствуются учителя, выстраивая работу на уроке: групповую, в парах, индивидуальную. В частности, результаты мониторинга выявляют приоритеты при конструировании содержания этапов уроков в соответствии с ФГОС ОО, тем самым, повышая качество образовательного процесса в школе.

План внутришкольного контроля включает мероприятия по диагностике компетентностей педагогов школы:

1. По уровню методики преподавания учебных дисциплин учителями. Анализ урока методистом-администратором проводится очень подробно, оценивается критериально деятельность педагога и обучающихся на разных этапах в соответствии с ФГОС:

- Оценка основных личностных качеств учителя на уроке (знание предмета и общая эрудиция учителя в целом, культура речи и умение взаимодействовать с классом, степень тактичности и демократичности взаимоотношений с обучающимися);

- Основные этапы урока (мотивация, целеполагание, актуализация опорных знаний, содержание учебного материала и содержание образования, рефлексия, оценка результатов урока, домашнее задание);

- Оценка основных характеристик обучающихся на уроке (степень их познавательной активности, степень самостоятельности и уровень сформированности организационных, информационных и логических УУД, степень дисциплинированности, организованности и заинтересованности);

- Оценка эффективности и грамотности организации урока (соответствие этапов урока требованиям системно-деятельностного подхода, рациональность и эффективность использования времени урока, оптимальность его темпа, а также чередования и смены видов деятельности, формы организации познавательной деятельности обучающихся, методы обучения, уровень обратной связи со всеми обучающимися в ходе урока и эффективность контроля, эстетика урока, соблюде- 
ние правил ОТ и ТБ)

- Оценка результатов проведенного урока (степень обучающего воздействия урока на обучающихся).

Подробный анализ уроков позволяет сделать выводы о методической грамотности педагогов при подаче программного материала, а также о компетентности по развитию метапредметных умений на уроках.

2. Умению педагогов организовывать работу со слабоуспевающими детьми и детьми, имеющими высокую мотивацию к обучению:

- наличие, разработка и реализация индивидуального учебного плана,

- вовлечение в проектную деятельность,

- участие в олимпиадах, конкурсах и т.д.

Подробный анализ работы учителя на уроке с детьми показывает его умение работать над развитием метапредметных умений на уроке, в частности, логических умений, мониторинг которых проводится в школе. Данная диагностика остается констатирующей, не дающей ответ на главный вопрос - что делать со статистическими данными, которые появляются в итоге, как их изменить, повысить уровень необходимых умений у обучающихся по результатам диагностики?

Для групп педагогов на первом этапе построения модели повышения качества и обеспечению доступности образования возможно проведение серии семинаров по изучению логических умений и работе над ними на уроках с обучающимися. Каждое семинарское занятие позволяет глубоко проработать понимание, формирование одного логического умения и состоит из теоретической и практической частей. В теории педагоги учатся понимать структуру логического умения с научной точки зрения как действие, которое при правильной постановке вопросов может быть доведено до логического завершения. В практической части семинарского занятия учителя работают с содержанием учебников: находят задания, которые помогают раскрыть конкретное логическое умение, дорабатывают их, дополняя необходимыми вопросами, раскрывающими суть умения.

Для реализации плана построения эффективной модели повышения качества и обеспечения доступности образования необходимо грамотное осуществление менеджмента в организации. Очень важно, чтобы управленческая команда:

- умело планировала и анализировала свою работу в долгосрочной перспективе (имела программу развития школы),

- в течении учебного года работала в соответствии с методической темой,

- проводила триместровый (по четвертям) анализ деятельности на производственных совещаниях,

- грамотно организовывала еженедельное опера- тивные совещания.

При реализации планов очень важно управленческой команде:

- проявлять последовательность и системность,

- оперативно реагировать в случае необходимости,

- быть справедливым в решении вопросов,

- поддерживать положительный психологический климат в коллективе.

Для успешной реализации образовательных целей в современной школе важное место занимает вопрос о материальном обеспечении. От директора зависит:

- в каком состоянии находится техническое оснащение школы,

- производится ли материальное стимулирование педагогов,

- возможно ли пригласить дополнительных специалистов (на постоянной основе, гостей),

- открытие новых направлений деятельности, организованных административной командой.

\section{2 этап практический}

Цель второго этапа - создание направлений дистанционной работы для осуществления обучения учащихся, педагогов, создание школы молодого педагога, учителяпрактика, программы управления коллективом.

На данном этапе проводится продолжение мониторинговых мероприятий и на их основе систематизация и структурирование Модели по повышению качества и обеспечению доступности образования для трех группучастников.

\section{Обучаюшиеся}

Результаты предметного и метапредметного мониторингов выносятся на обсуждение психолого-педагогических консилиумов в начале и в конце учебного года для проблемно-аналитического анализа уровня индивидуального развития обучающихся и коллектива класса. Задачами консилиумов также являются:

- Сравнительный анализ входной диагностики с эталонным портретом обучающихся определенного возраста.

- Разработка индивидуальных задач развития и воспитания обучающихся и класса в целом на основе рекомендаций специалистов и экспертов.

- Определение стратегии по реализации задач развития и воспитания обучающихся.

По итогам консилиумов создается пакет документов для педагогов школы для организации коллективной и индивидуальной работы с обучающимися. Данный пакет документов входит в основу образовательной программы класса, использовать материалы которой могут все 
педагоги, работающие с обучающимися данного класса. В образовательную программу класса входят:

- психолого-педагогическая характеристика клас$\mathrm{ca}$,

- коллективные задачи развития класса,

- индивидуальные задачи развития обучающихся,

- возрастные особенности детей данного возраста (психолого-педагогический портрет обучающихся данного возраста),

- результаты предметного, метапредметного мониторингов,

- стратегия реализации задач воспитания и развития обучающихся (SWOT-анализ).

Результаты диагностических процедур, аналитических материалов психолого-педагогических консилиумов позволяют построить более качественно работу с обучающимися, требующими индивидуального подхода в построении их образовательного маршрута. К ним относятся категории детей, которые часто и долго болеют, уезжают во время учебного процесса за пределы страны, имеют индивидуальные особенности при освоении программного материала, высокомотивированные дети. Для них создание дистанционной формы получения образования является очень востребованной, необходимой.

\section{Педагоги}

Разработка дистанционного направления работы с обучающимися породила программу работы с ними и появление новых компетенций педагогов. Использование дистанционной платформы CMS moodle предопределило для группы педагогов необходимость в освоении навыков технического редактора, программного разработчика обучающих курсов, тьютора. Тьюторы сопровождают учебный процесс обучающегося, перешедшего на очно-заочную, заочную форму обучения. Они формируют задание учителям-предметникам в подготовке учебного материала для выкладки его на сайт, на котором организуется дистанционная форма работы с детьми. Учителя-предметники структурируют материал учебников под инструменты сайта, с помощью которых учебный материал выкладывается в интернет-среду. Инструменты сайта позволяют учебный материал увидеть в электронном виде, изучить его, пройти тестирование, оставить комментарии, увидеть оценку своих действий, взаимодействовать с педагогом удаленно. Нередко педагоги, осваивающие навыки разработчика электронных обучающих курсов, становятся техническими редакторами данных курсов. Таким образом, ответственность за переработку материалов учебно-методического комплекса по определенной дисциплине и за выкладку их в электронную среду берет на себя один педагог.

Для подготовки к появлению нового вида учебной деятельности, дистанционного обучения, необходимо вре- мя. Его в течение учебного года не хватает. Время можно найти в рабочие дни летнего периода после первого года реализации Модели. Перед уходом в отпуск организуется группа педагогов, которая проходит обучение у куратора данного направления. Педагоги, осваивающие технологию дистанционного обучения, получают знания педагога-тьютора, разработчика электронных курсов и технического редактора сайта. Данная группа специалистов приступает к практической работе - созданию электронных курсов по учебным дисциплинам, входящим в учебный план того класса, по обучению в котором появился запрос на следующий учебный год. Таким образом, основа для дистанционной работы с детьми появляется летом, а в течении учебного года происходит доработка электронных курсов ведущей группой техредакторов и теми педагогами, которые присоединились к данной работе в процессе.

Необходимость осваивать новые технологии работы всеми педагогами продиктовано временем. С появлением электронного образовательного ресурса появляется возможность модернизации своей работы, оперативности и удобства использования методических материалов, обмена всеми документами школы, кафедры, методического объединения. ИКТ-компетентность позволяет педагогам эффективно работать с электронным кабинетом ученика-заочника, использовать документы электронной страницы методического объединения, располагать и обмениваться материалами электронной методической копилки, быть активным участником обучающих направлений «Копилки учителя-практика» и «Школы молодого педагога».

Направления «Копилка учителя-практика» и «Школы молодого педагога» возникли из диагностики первого этапа Модели, после изучения аналитических материалов. Содержание данных направлений также частично трансформируются на электронный ресурс школы.

Организация работы «Школы молодого педагога» включает:

1. посещение, анализ, методические рекомендации рабочих уроков молодых учителей методистом внутри ОУ;

2. проведение семинарских занятий методистом в соответствии с планом по знакомству с методиками и технологиями ведущих педагогических практик.

В содержание «Копилки учителя-практика» входит:

1. работа на семинарских занятиях в соответствии с планом по овладению методиками и технологиями ведущих педагогических практик;

2. проведение открытых уроков с целью позиционирования нового опыта;

3. проведение предметных недель; 
4. проведение дней открытых дверей для родителей, педагогов ОУ;

5. участие учителей-практиков, владеющих различными педагогическими технологиями, в тематических мероприятиях.

Учителя-участники направлений «Копилка учителя-практика» и «Школа молодого педагога» работают в тесном взаимодействии друг с другом. Рождается направление «Наставничество», имеющее программу корпоративного обучения - осеннюю, зимнюю, весеннюю сессии.

\section{Администрачия}

Методическая работа в школе нацелена на создание нового эффективного опыта работы учителя, развитие личности педагога, рост его профессионального мастерства. Администрация является при этом центральным звеном, активным инициатором развития новых направлений, стимулирующим фактором при достижении положительных результатов. Администрацией в ходе аналитической работы по результатам деятельности педагогов определяются группы сотрудников, в отношениях с которыми выстраивается определенных стиль коммуникации. Администратор выделяет несколько психологических типов человеческого восприятия и принятия нововведений педагогами, выстраивает свои действия по отношению к подчиненным в зависимости от определенной группы, к которой относится педагог:

1. Педагог владеет определенной педтехнологией, но применять ее не хочет. Действия администрации: человек в приоритете, ему надо создать ситуацию успеха, режим работы с ним «поддерживающий».

2. Педагог владеет определенной педтехнологией и хочет ее применять. Действия администрации: режим с работы с ним «делегирующий», выполнение задачи в приоритете, человек и сам все умеет и сделает.

3. Педагог не владеет определенной педтехнологией, но применять ее хочет. Действия администрации: человек в приоритете, его надо научить, режим работы с ним «наставничество».

4. Педагог не владеет педтехнологией и не хочет ею овладеть.

Действия администрации: режим работы с ним «директивный», выполнение задачи в приоритете, а человека можно и наказать.

\section{З этап - развиваюший}

Цель данного этапа - расширение, дополнение имеющихся направлений работы в образовательном учреждении.
Развитие Модели на следующем этапе, в основном, осуществляется расширением направлений работы обучающихся и педагогов:

1. Обучающиеся:

- появляются возможности тьюторского сопровождения не только групп детей, которые испытывают затруднения в обучении, но и адресная помощь высокомотивированным детям;

- развитие дистанционного направления работы позволяет охватить большое количество обучающихся, тем самым, создать заочное отделение школы с количеством обучающихся, возможно, превышающим очное отделение.

\section{2. Педагоги:}

На основе разработанных методических материалов «Копилки учителя-практика», «Школы молодого педагога», возможностей электронного портала школы создание курсов повышения квалификации не только педагогов одной школы, но и муниципалитета, региона.

3. Администрация осуществляет позиционирование направлений деятельности школы за ее пределами через:

- участие в городских, региональных мероприятиях системы образования,

- проведение для работников системы образования очных тематических семинаров,

- создание дистанционных курсов повышения квалификации педагогов.

Данная Модель системы по повышению качества и обеспечению доступности образования открытая. Продолжительность и содержание каждого ее этапа полностью зависит от третьей ее группы - администрации.

Стиль руководства образовательной организацией, организационно-правовая форма образовательного учреждения - факторы, влияющие на успешную реализацию Модели.

Демократический стиль руководства характеризуется привлечением подчиненных, общественности к участию в подготовке и принятии управленческих решений. Он зависит от профессионализма руководителя, уровня развития педагогического и школьного коллектива, характера решаемых задач, благоприятных внешних условий, от конкретной ситуации. Наиболее эффективен демократический стиль руководства на стадии разработки и обсуждения решений, особенно - стратегических и инновационных, таких как начало деятельности по созданию Модели системы по повышению качества и обеспечению доступности образования. Далее на второй и третьих ступенях реализации Модели в зависимости от личностных качеств участников педагогического коллектива возможны идеи демократических отноше- 
ний либо сочетание демократического и авторитарного стилей. Наиболее эффективен либеральный стиль руководства при реализации инновационных идей. Он возможен в школах со сложившимися, высокоразвитыми, нравственно здоровыми и творчески работающими коллективами, в условиях руководства творческими группами, школьными кафедрами, в отношениях руководителя с наиболее опытными, квалифицированными и ответственно относящимися к своим обязанностям работникам, с педагогами-исследователями, разработчиками авторских программ, инновационных технологий.

Организационно-правовая форма образовательного учреждения, учредителем которого не являются органы государственной власти Российской Федерации, имеет преимущество в выборе средств, ресурсов, времени для реализации Модели. Это не значит, что результаты могут быть удачны в такой образовательной организации. Ведущим в данном случае является стиль руководства педагогическим коллективом. А он не всегда может быть демократическим или, тем более, либеральным.

Эффективный менеджмент в образовательной организации, появление и освоение новых компетенций педагогами при работе на онлайн-платформе предопределяют успех реализации Модели системы по повышению качества и обеспечению доступности образования.

\section{ЛИТЕРАТУРА}

1. Указ Президента РФ от 07.05.2018 № 2040 национальных целях и стратегических задачах развития Российской Федерации на период до 2024 года (с изменениями на 19 июля 2018 года)

2. Распоряжение Правительства РФ от 31 декабря 2019 г. N 3273-р «0б утверждении основных принципов национальной системы профессионального роста педагогических работников РФ, включая национальную систему учительского роста».

3. Распоряжение Минпросвещения России от 17.12 .2019 N P-140 «06 утверждении методических рекомендаций по созданию центров непрерывного повышения профессионального мастерства педагогических работников и центров оценки профессионального мастерства и квалификации педагогов в рамках региональных проектов, обеспечивающих достижение целей, показателей и результатов федерального проекта «Учитель будущего» национального проекта «0бразование».

4. Хлопкова 0.В. Мониторинг логических умений обучающихся общеобразовательной школы. - Ж. Среднее профессиональное 0бразование, 2018, №2. - 54 с.

(с) Хлопкова Оксана Викторовна (okshlopkova3@bk.ru)

Журнал «Современная наука: актуальные проблемы теории и практики»

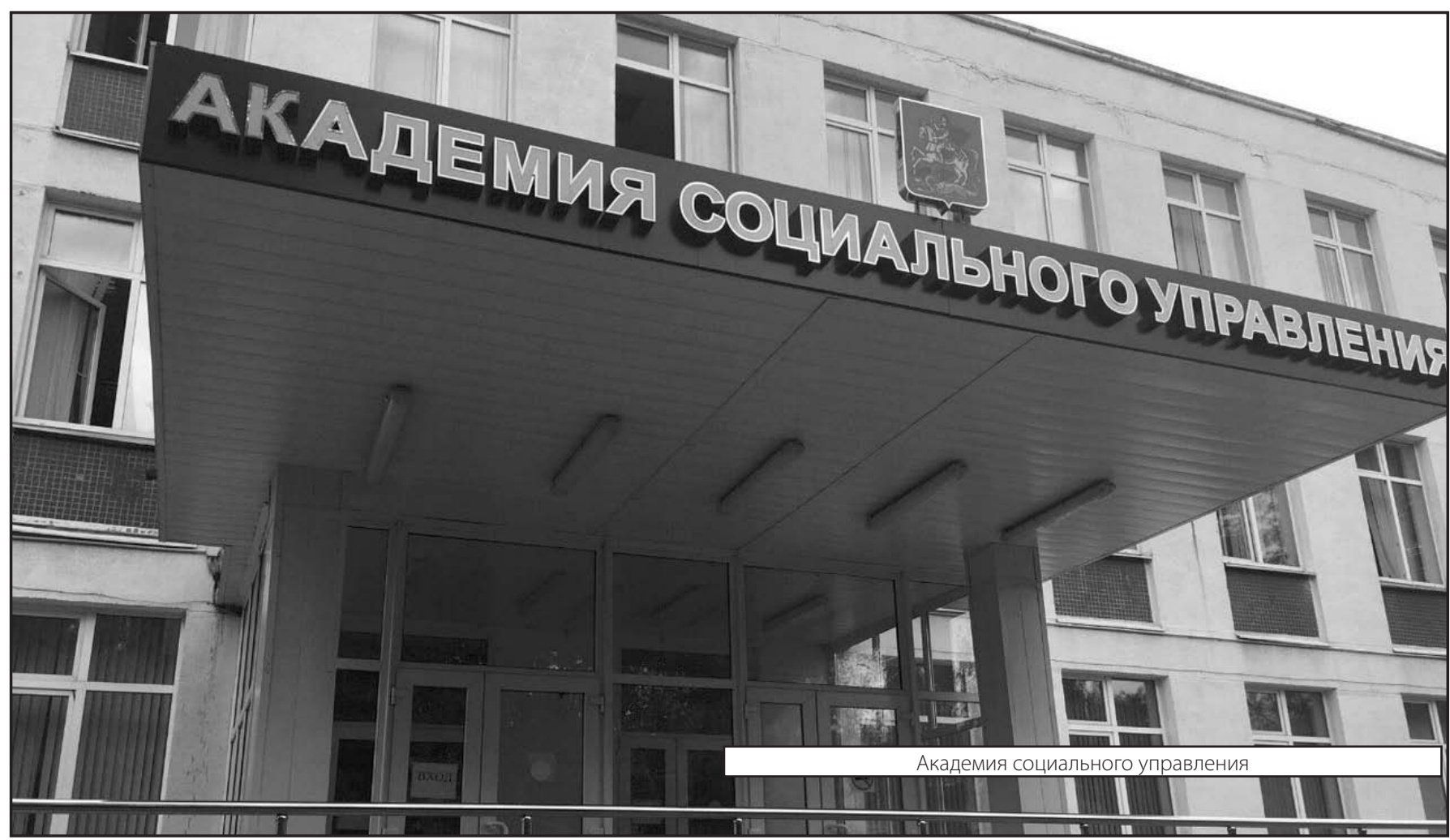

